\title{
Students’ Perception on Interprofessional Education
}

\author{
Salmah Orbayinah, Laksmi Putri Utami \\ School of Pharmacy, Faculty of Medicine And Health Science, University Muhammadiyah Yogyakarta, Indonesia
}

\begin{tabular}{l} 
Article Info \\
\hline Article history: \\
Received Aug 15, 2015 \\
Revised Nov 20, 2015 \\
Accepted Nov 26, 2015 \\
\hline
\end{tabular}

\section{Keyword:}

Interprofessional Education

Perception

Student

\begin{abstract}
Unawareness of the roles and competencies of other health professions has led to many medical and medication errors in the treatment of patients in the hospital. It is considered important to give Interprofessional Education (IPE) to students at pre-clinic and clinical stage in order to have a good understanding about roles of other health professionas. IPE is an interprofessional collaborative learning to support promotive, preventive, curative, rehabilitative and other approches related to health aspect. Perception is among the most important and highly needed skill in the implementation of IPE. This research aimed to determine the effect of IPE learning toward the perception among the students in Faculty of Medicine and Health Science of Universitas Muhammadiyah Yogyakarta (FMHS UMY). This is an observational study adopting a cross sectional design. The sample of students was collected through purposive sampling technique. A number of 94 students met the inclusion criteria, comprised of 21 students of Medical Profession Education, 25 of Dentistry Profession Education, 25 of Nursing Profession Education and 21 Undergraduate students of Pharmacy. Samples were given questionnaire of Interdiciplinary Education Perception Scale. Comparative test was done by Kruskall-Wallis test. From 94 students of FMHS, 75.5\% had good perception toward IPE. No significant differences appeared in perception $(\mathrm{p}=0.285)$ among the students of FMHS UMY. The Interprofessional Education (IPE) had significant effects toward the perception among the students of FMHS UMY.
\end{abstract}

Copyright () 2015 Institute of Advanced Engineering and Science. All rights reserved.

\section{Corresponding Author:}

Salmah Orbayinah

School of Pharmacy,

Faculty of Medicine And Health Science of University Muhammadiyah Yogyakarta,

Jl. Lingkar Selatan, Tamantirto, Kasihan, Bantul, Yogyakarta, Indonesia.

Email: orbayinah_salmah@yahoo.com

\section{INTRODUCTION}

Healthcare providers have a responsibility to give an optimum service to the patient in order to increase patients' quality of life. Medical and medication errors are examples of human errors that must be avoided to give such service. This can be achieved through a good and effective collaboration among healthcare providers [1]. Initiating an effective collaboration for this purpose should then be introduced in the education system or curricula of healthcare professionals.

World Health Organization itself has stated that implementing interprofessional collaboration in the education system as well as in healthcare practice would have an impact on reducing errors in the healthcare services globally. The aim of collaborative practice is to strengthen the healthcare system and improve the outcome of health services [2]. Therefore, a study group on interprofessional education was initiated in 2007 by WHO to spread awareness on the need of IPE to the world.

Interprofessional Education is defined as a process wherein a group of students or health care workers from various professional background learn together for a defined period of time to collaborate in promoting promotive, preventive, curative, rehabilitative and other approaches related to health care system [3]. In interprofessional education, students of various healthcare backgrounds would do observation and 
discuss about how to build good collaboration between healthcare providers in clinical settings. The students would then be noticed on the knowledge, attitude, and skills that should be developed in order to conduct an effective interprofessional collaboration for the sake of their patients [4].

IPE in Indonesia is beginning to be acknowledged by some educational institution for health professions as a necessity in their curricula. Unawareness of the roles and competencies of other health professions has led to many medical and medication errors in the treatment of patients in the hospital. This lack of understanding can be overcome by exposure of IPE in the pre-clinical and clinical stages of their educational system.

FMHS UMY as one of the education institution for healthcare professionals consisting of School of Medicine, School of Dentistry, School of Nursing, and School of Pharmacy has begun conducting IPE since 2012 through various simulation projects. IPE was then integrated in the curricula since 2013, initiating a collaborative work between students from four departments in managing various kinds of patients. Results from previous studies revealed that IPE in FMHS UMY can improve collaboration attitudes among the students [5].

\section{RESEARCH METHOD}

\subsection{Research Design}

This is an observational study adopting a cross sectional design.

\subsection{Time and Place of Research}

This research was conducted at Faculty of Medical and Health Sciences (FMHS), Universitas Muhammadiyah Yogyakarta (UMY) and Asri Medical Centre (AMC) from June to September 2014.

\subsection{Population and Sample}

Population of this research are students from 4 departments of FMHS UMY joining the IPE program. The sample of students was collected through purposive sampling technique from June to September 2014.

\subsection{Research Variables}

The research variables included:

a. Free Variables: IPE Learning

b. Dependant Variables : FMHS Students’ Perception on IPE

\subsection{Research Instrument}

Instrument used in this research was questionnaire, which was a modification from the Interdiciplinary Education Perception Scale (IEPS)

\subsection{Operational Procedure}

The Operational Procedure of the research was divided into several steps:

1. Preparation

In this step, study of literatures is conducted to have an insight on interprofessional education for healthcare providers

2. Implementation Researcher collect data from students of FMHS that had been exposed to IPE. Data collected consisted of demographic data and data from the IEPS questionnaire

3. Data Analysis

Researcher analyze the collected data, drew a conclusion and wrote the result as a research report.

\subsection{Data Analysis}

Variables were described in a table of frequency distribution and percentage (\%) on level of perceptionfor which the data scale was in ordinal form. The next step was carrying out data normality test. Data with normal distribution was then compared using One Way ANOVA. While data which did not show a normal distribution was analyzed using Kruskall-Wallis test. 


\section{RESULTS AND ANALYSIS}

\subsection{Characteristics of Respondents}

Characteristics of respondents participating IPE in FMHS UMY are shown in Table 1.

Table 1. Characteristics of each respondents attended IPE at FMHS UMY [5]

\begin{tabular}{lcc}
\hline \multicolumn{1}{c}{ Characteristic } & Frequency & Percentage (\%) \\
\hline Medical Profession Program & 23 & 24.46 \\
Dentistry Profession Program & 25 & 26.59 \\
Nursing Profession Program & 25 & 26.59 \\
Pharmacy Undergraduate & 21 & 22.34 \\
$\quad$ Total Respondents & 94 people & $100 \%$ \\
\hline
\end{tabular}

Respondents were obtained from the 4 departments or program in FMHS UMY. Students from medical, nursing, and dentistry were from the professional degree program while pharmacy students were from the undergraduate students from School of Pharmacy that have been given clinical theories and skills in order to be able to conduct collaborative practice with the other groups.

\subsection{Students’ Perception toward IPE}

Data on students' perception toward IPE comprised of four components, namely Competency and autonomy, Needs for collaboration, Collaboration evidence and Understanding on other professions. The measurement result on the value of Perception of FMHS students toward IPE is presented in Table 2.

Table 2. Distribution of Frequency on Perception toward IPE

\begin{tabular}{cccc}
\hline No & Category & Frequency (f) & Percentage (\%) \\
\hline 1 & Good & 71 & 75.5 \\
2 & Adequate & 22 & 23.4 \\
3 & Low & 1 & 1.0 \\
4 & Poor & 0 & 0 \\
\hline
\end{tabular}

The table above showed that students of FMHS UMY had good perception toward IPE, represented in percentage of $75.5 \%$, while the rest of students were stated to stay at Adequate level, with the percentage of 23.4\% and 1\% in Low level. According to Morison [5], students with good perception toward IPE during the class are potentially able to develop their interprofessional relation in giving health treatment toward patients when working as professional health workers. The students who are accustomed to learn in the environment that promotes interprofessional collaboration would develop good perception toward IPE [6].

To find whether there is any significant difference of perception between IPE among the four departments involved in this research, namely Medical Education, Dentistry Education, Nursing Education and Pharmacy Education Program at FMHS UMY, a comparative test was conducted. This test employed non-parametric test of Kruskall-Wallis. Based on Kruskall-Wallis test, there was no significant difference among the four departments at FMHS UMY on the perception toward IPE ( $>00.05)$.

To know further about the students' perception toward IPE, an analysis on the perception component, consisting of competence and autonomy, perception on the need to collaborate, collaboration evidence and inter professional understanding is shown on Table 3.

Table 3. A frequency distribution on the components of the perception on IPE among students of FMHS UMY

\begin{tabular}{|c|c|c|c|c|c|c|c|c|c|}
\hline \multirow{2}{*}{ No } & \multirow{2}{*}{ Component } & \multicolumn{2}{|c|}{ Good } & \multicolumn{2}{|c|}{ Adequate } & \multicolumn{2}{|c|}{ Low } & \multicolumn{2}{|c|}{ Poor } \\
\hline & & $\mathrm{F}$ & $\%$ & $\mathrm{~F}$ & $\%$ & $\mathrm{~F}$ & $\%$ & $\mathrm{~F}$ & $\%$ \\
\hline 2 & Needs for collaboration & 75 & 79.8 & 18 & 19.1 & 1 & 1.1 & 0 & 0 \\
\hline 4 & Understanding on other professions & 47 & 50.0 & 46 & 48.9 & 0 & 0 & 1 & 1.1 \\
\hline
\end{tabular}

Based on the table above, all components of the students had good perception on IPE such as competency and autonomy, needs for collaboration, collaboration evidence, and interprofessional 
understanding in health care scheme. The highest percentage was for the component of collaboration evidence (81.1\%).

In the comparative test using Kruskall-Wallis on the components of perception on IPE among the students from four departments, it is revealed that only the component of collaboration evidence $(\mathrm{p}=0.0011)$ showed significant difference on the students from four departments.

\section{CONCLUSION}

The interprofessional education (IPE) has significant effects toward the perception among the students of Medical Faculty UMY. The students of Medical Faculty UMY have good perception toward the IPE. There is no significant difference on the perception toward Interprofessional Education among the students of Medical Faculty UMY.

\section{REFERENCES}

[1] American College of Clinical Pharmacy, "Interprofessional Education: Principles and Application, a Faramework for Clinical Pharmacy”, Pharmacotherapy, vol/issue: 29(3), pp. 145-164, 2009. Diakses dari http://www.accp.com/docs/positionswhitePapers/InterProfEduc.pdf pada tanggal 18 mei 2014.

[2] World Health Organization, "World Health Organization Study Group on Interprofessional Education and Collaborative Practice”, 2010.

[3] Canadian Interprofessional Health Collaborative (CIHC), "What is Collaborative Practice, 2009.

[4] Glen, S., Revees, S., "Developing interprofessional education in the pre-registration curricula: mission imposible?”, Nurse Education in Practic, vol. 4, pp. 45-52, 2003.

[5] Orbayinah, S., Utami, LP., "Impact of Interprofessional Education on Collaboration Attitudes Among The Student of Medical Faculty and Health Sciences Universitas Muhammadiyah Yogyakarta”, Journal of Health, Medicine, and Nursing, vol. 17, pp. 97-100, 2015.

[6] Morison, S., Boohan, M., Moutray, M., Jenkins, J., “Developing Pre-Qualification Interprofessional Education For Nursing and Medical Student: Sampling Student Attitude To Guide Development”, Nursing Education in Practice, vol. 4, pp. 20-29, 2003. 